power they deserve as professionals and to exercise it individually, collectively and in concert with other professionals to promote better and more costeffective health care for all persons, especially those who have least access to it'.

The position taken in these papers is that if nurses are to act in a professional way they must have the power to enable them to do so. The nurse's role is said to be that of patient advocate within the complex organisational settings of health care. Nurses have responsibilities to patients, to the organisation and, if professional status is to be achieved and sustained, to their professional association. In trying to respond to these responsibilities, the nurse encounters ethical issues and may be faced with moral dilemmas.

Thompson's paper, Conflicting Loyalties of Nurses Working in Bureaucratic Settings, addresses these ethical issues. The paper centres on the case of a mother who asks to hold her baby (after a normal delivery) and is met with some unwillingness on the part of the nurse, who wants to weigh the baby and place it in the 'warmer'. The questions Thompson raises from this everyday type of situation are 'How is it that child-bearing women have to ask if it is all right to hold their own baby?'; 'What has happened to hospitaloriented childbirth that it is forcing some couples to choose out-of-hospital care, or no care at all rather than submit their bodies and normal life experiences to the control of others - doctors, midwives and nurses?'; 'Who makes hospital policies and for whose benefit are these policies made?'
Thompson's main argument is that nurses should examine their daily practice, looking especially at the ethical aspects of their decisionmaking. If nurses are to 'live up to their status as professionals they must,' she argues, 'practise in an ethical manner, and this means studying ethics in order to determine what is ethical practice'. It has to be said that, as with some of the other papers in this collection, the questions make rather more interesting reading than the attempts to address them. One does not expect the impossible to be achieved in that answers are produced to ethical dilemmas, but a little more imaginative discussion would have been welcome. Exceptions to this disappointing trait are to be found in the papers by Margretta Styles and Richard Hall.

In all it is a useful collection, with the emphasis laid more upon professionalism and power than ethical debate.

KATH M MELIA

Lecturer, Department of Nursing Studies Faculty of Social Sciences University of Edinburgh

\section{Health, Disease, and Causal Explanations in Medicine}

Editors, Lennart Nordenfelt, B Ingermar and B Lindahl, 256 pages, Dordrecht/Boston/Lancaster, D Reidel, 1984.

Medical ethics is a subject which by now is familiar and acceptable to most doctors, but, because of its stronglym normative aspects is not acceptable to $\overrightarrow{2}$. all philosophers as a part of philosophy The reverse may be true of the philosophy of medicine, a disciplines which because of its highly theoreticat and conceptual nature is nearer to the main stream of philosophy and further from the practical concerns of doctors $\overparen{\Phi}$ This book offers essays of a philosophical nature on the concepts of health and disease, and the various ways in which the concept of causality is involved in our understanding of these $\vec{\omega}$ concepts. Several of the essays deal witho the analysis of different models of health and disease. For example, ${ }^{\mathbb{D}}$ biological, descriptive views are $\overrightarrow{-}$ contrasted with evaluative views and the question considered what is the primary subject of health - the wholee person or the parts of the body. There is? discussion of definition and classification in medicine and of causality in general as well as in medicine. Apart from discussions of a philosophically familiar kind on $\overrightarrow{0}$ causality there is an interesting sections on causal assumptions in holistiq medicine. This is a worthwhile book which makes a real contribution to ours understanding of various conceptuap problems in medicine, but it is not foin the philosophical beginner. The authors are a mixture of scientists, $\overrightarrow{\overrightarrow{\widehat{B}}}$ physicians, social scientists and philosophers and the book is the outcome of a symposium in Stockholm - the first Nordic Symposium on the Philosophy of Medicine.

R S DOWNIE Professor of Moral Philosophy, Glasgow University 